in vivo $34: 549-556(2020)$

doi:10.21873/invivo.11807

\title{
18-kDa Translocator Protein Ligands Protect H9C2 Cardiomyocytes from Cigarette Smoke-induced Cell Death: In Vitro Study
}

\author{
RAFAEL NAGLER ${ }^{1}$, NIDAL ZEINEH ${ }^{1}$, MAYA AZRAD $^{1}$, NASRA YASSIN $^{1}$, \\ ABRAHAM WEIZMAN $^{2,3}$ and MOSHE GAVISH ${ }^{1}$ \\ ${ }^{1}$ Department of Neuroscience, Faculty of Medicine, Rappaport Family Institute for Research in the Medical Sciences, \\ Technion - Israel Institute of Technology, Haifa, Israel; \\ ${ }^{2}$ Research Unit at Geha Mental Health Center and Laboratory of Biological Psychiatry \\ at Felsenstein Medical Research Center, Petah Tikva, Israel; \\ ${ }^{3}$ Sackler Faculty of Medicine, Tel Aviv University, Tel Aviv, Israel
}

\begin{abstract}
Background: Cigarette smoke (CS) can induce cellular damage via alterations in $18 \mathrm{kDa}$ translocator protein (TSPO)-related functions, leading to cardiovascular diseases. The current study focused on the possible protective effect of TSPO ligands against CS-induced damage to cardiac cells. Materials and Methods: H9C2 Cardiomyocyte cell line of rat origin was pre-treated with TSPO ligands. Cell death, TSPO binding, and TSPO protein expression levels were assessed following 30-min CS exposure with/without TSPO ligands. Results: CS exposure of $\mathrm{H} 9 \mathrm{C} 2$ cells significantly incensed cell death (by 26\%, p<0.001). Pre-treatment with TSPO ligands at two concentrations prevented cell death. Neither CS nor ligands affected TSPO protein expression in H9C2 cells. CS led to increased cell death and reduced TSPO binding. Conclusion: Reduced TSPO binding may have a role in CS-induced cell death, and TSPO ligand MGV-1 can prevent suppression of TSPO binding and corresponding cell death. These results may be relevant to treatment of cardiovascular diseases associated with CS.
\end{abstract}

The $18 \mathrm{kDa}$ translocator protein (TSPO) is involved in various cellular functions, including regulation of cell death and

This article is freely accessible online.

Correspondence to: Professor M. Gavish/Professor R.M. Nagler, Department of Neuroscience, Faculty of Medicine, Rappaport Family Institute for Research in the Medical Sciences, Technion Israel Institute of Technology, Haifa, Israel. Tel: +972 48295275, Fax: +972 48295271, e-mail: mgavish@tx.technion.ac.i1/nagler@ tx.technion.ac.il

Key Words: Cigarette smoke, TSPO ligands, cardiomyocyte cell line, H9C2, LDH. expression of various genes (1-6). The primary locations of TSPO include the outer mitochondrial membrane, and nuclear and perinuclear sites $(4,7,8)$. TSPO can be found throughout the body in various tissues $(4,9)$. Our group has previously reported that following exposure to cigarette smoke (CS), TSPO binding affinity is reduced both in vivo and in vitro (10).

Tobacco use in general and CS in particular cause nearly 6 million deaths per year worldwide, and current trends show that this rate will increase to more than 8 million deaths annually by 2030 (11). On average, smokers die 10 years earlier than non-smokers (12), and the total economic cost of smoking in the US alone is more than $\$ 300$ billion a year (13). More than 16 million Americans are living with a disease caused by smoking; for every person who dies due to smoking, at least 30 people live with a serious smokingrelated illness. Smoking causes lung and other kinds of cancer, cardiovascular diseases, stroke, diabetes, and chronic obstructive pulmonary disease, including emphysema and chronic bronchitis (13-18). The underlying mechanisms of the damage caused by toxic compounds inhaled from CS-is not understood. A single cigarette contains nine inhalations, and each of which containing about 5,000 toxic compounds, including free radicals and various carcinogens (19). Cessation of smoking, or avoidance in the first place, is the preferable way to reduce disease incidence; however, due to social factors and the highly addictive nature of cigarette smoking, the option of avoidance is often unlikely. Moreover, immunological and biological changes affecting smokers are not completely reversible even after smoking cessation (20). Thus, treatment for damage caused by CS is an unmet need.

TSPO ligand 2-phenylquinazolin-4-yl dimethylcarbamate (MGV-1) and 2-(2-chlorophenyl) quinazolin-4-yl dimethylcarbamate (2-Cl-MGV-1) (21) were developed by expansion 
of a quinazoline scaffold. Inhibitory effects on inflammatory reactions of these have been described (22). TSPO has low affinities for these ligands (both approximately $825 \mathrm{nM}$ ) due to their elongated alkyl side chains, which results in reduced lethal effects as compared to the classical TSPO ligands as described previously $(21,23)$.

The current study focused on the possible protective effect of TSPO ligands against CS-induced damage to cardiac cells.

\section{Materials and Methods}

Cells and study design. In this study, rat cardiomyocyte H9C2 cell line was used. The cells were maintained as described by the American Type Culture Collection (ATCC, Manassas, VA, USA): culture medium consisted of Dulbecco's modified Eagle's medium (high glucose, with no L-glutamine and no sodium pyruvate), supplemented with fetal bovine serum (10\%), glutamine (2\%), sodium pyruvate $(1 \%)$ and penicillin-streptomycin solution $(\times 10)$ $(0.1 \%)$. The cells were grown at $37^{\circ} \mathrm{C}$ in $5 \% \mathrm{CO}_{2}$ for $48 \mathrm{~h}$ to reach $80 \%$ confluency, then incubated for $24 \mathrm{~h}$ with or without either the tricyclic, quinazoline-based TSPO ligand 2-(2-chlorophenyl) quinazolin-4-yl dimethylcarbamate (2-Cl-MGV-1) or 2phenylquinazolin-4-yl dimethylcarbamate (MGV-1) (21). TSPO has low affinity for these ligands (both approximately $825 \mathrm{nM}$ ) due to the elongation of the alkyl side chains, which reduces their lethal effects as compared to the classical TSPO ligands as described previously $(21,22)$. The anti-inflammatory effects of MGV-1 and 2-Cl-MGV-1 were described previously (23).

Initially, two concentrations of the ligands were used based on preliminary studies, 1 and $25 \mu \mathrm{M}$ final concentrations. Eventually, the chosen final concentration of the ligands in the current study was 25 $\mu \mathrm{M}$, as used previously $(22,23)$. Following incubation, the cells were exposed to CS for 30 and $60 \mathrm{~min}$ in order to optimize the cell death assays. The experimental groups were: i) Sham/negative control group grown in starvation medium with $1 \%$ ethanol (vehicle) exposed to ambient air; Positive control: ii) Cells grown in starvation medium with $1 \%$ ethanol (as in the control group) and exposed to CS; iii) Experimental group I: Cells treated with 2-Cl-MGV-1 or MGV-1 dissolved in ethanol in starvation medium (ligand and vehicle at $1 \%$ of the total volume) and exposed to ambient air; iv) Experimental group II: Cells grown in starvation medium treated with 2-Cl-MGV1 or MGV-1 dissolved in ethanol in starvation medium (ligand and vehicle at $1 \%$ of the total volume) and exposed to CS.

Exposure of $\mathrm{H} 9 \mathrm{C} 2$ cells to $\mathrm{CS}$. $\mathrm{H} 9 \mathrm{C} 2$ cells were seeded at different densities $\left[10^{6}\right.$ cells/petri dish for binding and western blot assays, $10^{3}$ cells/well in a 96-well plate for lactate dehydrogenase (LDH) assay, and $250 \times 10^{3}$ cells/well in 6-well plate for fluorescenceactivated cell sorting (FACS) analysis] and grown until they reached $80 \%$ confluence. Depending on the protocol, the medium of the dishes/plates was replaced by $1 \%$ ethanol-containing starvation medium (supplemented with $0.5 \%$ fetal bovine serum, instead of $10 \%$ ) and a ligand-containing starvation medium prepared prior to application; these $1 \%$ ethanol-containing and ligand-containing starvation medium were applied $24 \mathrm{~h}$ prior to CS exposure.

The study was carried out using cigarettes (filtered "Time" cigarettes; Dubek, Israel) containing $14 \mathrm{mg}$ of tar and $0.9 \mathrm{mg}$ of nicotine per cigarette combined with a source of lowered pressure system as previously described (24). In short: an open petri dish/plate with cell cultures submerged in starvation medium was placed in a sealed reservoir with a sidearm to which a cigarette was attached. A reproducible low pressure was created in the reservoir by a vacuum pump. When the attached cigarette was lit, a valve was opened and the smoke from the lit cigarette was drawn in until the entire cigarette had burned. According to previous work in our laboratory, a single cigarette smoked in the above apparatus produced smoke equivalent to nine inhalations (25). During the exposure to CS, the reservoirs were sealed with the smoke inside and incubated (26). This procedure was repeated every $15 \mathrm{~min}$ for 30 and $60 \mathrm{~min}$. Control samples were subjected to ambient air instead of CS.

Measurement of LDH enzyme activity. LDH is an enzyme that is released from cells when the cellular membrane is compromised, as is the case with cells after necrosis and late apoptosis (26). The release of $\mathrm{LDH}$ to the medium can be used to determine cell viability (27). We used the Cytotoxicity Detection Kit (LDH) (Roche pharmaceuticals, Basel, Switzerland) according to the manufacturer's instructions. Absorbance at $492 \mathrm{~nm}$ with reference at $620 \mathrm{~nm}$ was measured with a Zenyth 200 spectrophotometer (Anthos, Eugendorf, Austria) and the results were calculated and normalized according to the formula given by the manufacturer.

TSPO binding assay. The cells were scraped from $100 \mathrm{~mm}$ petri dishes in their culture medium after being exposed to CS. The cells were then centrifuged $\left(15,808 \times g, 45 \mathrm{~min}, 4^{\circ} \mathrm{C}\right)$. The pellets were suspended in $20 \mathrm{ml}$ of cold $\left(4^{\circ} \mathrm{C}\right)$ phosphate-buffered saline (PBS) and centrifuged again $\left(15,808 \times \mathrm{g}, 45 \mathrm{~min}, 4^{\circ} \mathrm{C}\right)$. The pellets were frozen and stored at $-20^{\circ} \mathrm{C}$ for further use. For further processing, the pellets were thawed and homogenized in $2 \mathrm{ml}$ of PBS using a Kinematika Polytron (Lucerne, Switzerland) (setting 6) for $10 \mathrm{~s}$. Protein concentration was determined by the Bradford method (28). Bradford solution for determination of protein concentration was obtained from Bio-rad, Munich, Germany. Bovine serum albumin (BSA) was used as a standard.

Binding of ${ }^{3} \mathrm{H}$-labeled PK 11195 to the cell membrane was then conducted. The reaction mixture contained $400 \mu \mathrm{l}$ of homogenized membranes (40 $\mu \mathrm{g}$ protein) and $25 \mu \mathrm{l}$ of ${ }^{3} \mathrm{H}$-labeled PK 11195 (New England Nuclear, Boston, MA, USA) (6 nM final concentration), in the absence (total binding) or in the presence of $10 \mu \mathrm{M}$ unlabeled PK 11195 (nonspecific binding). After $90 \mathrm{~min}$ incubation at $40^{\circ} \mathrm{C}$, the samples were vacuum filtered through Whatman $\mathrm{GF} / \mathrm{C}$, washed three times with $4 \mathrm{ml} 5 \mathrm{mM}$ ice-cold phosphate buffer and placed in vials containing $4 \mathrm{ml}$ of CytoScint (MP Biomedicals, Costa Mesa, CA, USA). Radioactivity was counted after $12 \mathrm{~h}$ with a $1600 \mathrm{CA}$ Tri-Carb liquid scintillation analyzer (Packard, Global Medical Instrumentation, INC, Ramsey, MN, USA). Specific binding was obtained by subtracting the nonspecific binding from the total binding.

Western blot. The assay was performed as previously described (29). Briefly, protein levels were measured by Bradford method using BSA as a standard. Equal amounts of protein were electrophoresed on sodium dodecyl sulfate polyacrylamide gel, transferred to a nitrocellulose membrane and blocked in 5\% non-fat milk. Then the membranes were immuno-blotted overnight at $40^{\circ} \mathrm{C}$ with the primary rabbit anti-rat TSPO (1:1,000; Abcam, Cambridge, UK). Mouse antihuman $\beta$-actin (1:10,000; Santa Cruz Biotechnology, Santa Cruz, CA, USA) was used as a loading reference. After washing with $0.1 \%$ PBSTween, the membranes were incubated with IgG secondary antibody 
linked to horseradish peroxidase (anti-rabbit IgG 1:20,000, anti-mouse IgG 1:10,000; Jackson Immunologicals, West Grove, PA, USA) in PBS-Tween for $1 \mathrm{~h}$ at room temperature. Binding of antibodies to the membrane was detected with the EZ-ECL-detection reagent (Biological Industries, Beit Haemek, Israel), and using Totallab Quant software analysis (Las4010) (TotalLab Ltd., Newcastle-Upon-Tyne, UK). The results were analyzed using densitometry.

TSPO measurement using FACS. Cells were trypsinized and collected with the medium. The cells were centrifuged $(660 \times g$ for $5 \mathrm{~min}$ ) then the medium was removed. The cells were fixed in $4 \%$ paraformaldehyde for 10 min then washed with PBS without $\mathrm{Ca}^{+2}$ and $\mathrm{Mg}^{+2}$. The cells were then resuspended in $800 \mu \mathrm{l}$ of PBS containing $0.2 \%$ Tween for $10 \mathrm{~min}$ in ice. The cells were washed again with PBS and resuspended in $100 \mu \mathrm{l}$ of PBS-Tween containing $3 \%$ BSA and anti-TSPO (1:100; Abcam). The samples were incubated overnight at $4^{\circ} \mathrm{C}$. The next day the cells were washed and resuspended in $100 \mu \mathrm{l}$ of PBS-Tween containing 3\% BSA and Alexa Fluor 488 AffiniPure Goat Anti-Rabbit IgG (1:1,000; Jackson Immunologicals). The mean fluorescence was measured using a FACS machine CyAN ADP (Beckman Coulter, Brea, CA, USA). The data were analyzed using FlowJo (FlowJo LLC, Ashland, OR, USA).

Statistical analysis. Data are expressed as mean \pm S.E.M. The program used for statistical analysis was GraphPad prism (GraphPad Software, San Diego, CA, USA). When comparisons of more than two groups were conducted, the one-way analysis of variance (ANOVA) was performed with Bonferroni's multiple comparisons post hoc test. When comparing only two groups, Mann-Whitney $t$-test was performed as appropriate. The criterion for statistical significance was $p<0.05$.

Ethics Committee approval. Since this was an in vitro study, no ethical approval was required.

\section{Results}

LDH enzyme activity. The LDH level in the medium was measured as an indicator for CS-induced cellular death. The mean results of 12 repetitions are presented in Figure 1. The results showed a significant increase in LDH levels following 30 and $60 \mathrm{~min}$ of CS exposure. In the case of 30 min CS exposure, cell death increased by $30 \%(p<0.001)$ as compared to the control group (Figure 1A). After 60 min of $\mathrm{CS}$ exposure, the cell death increased by $48 \%$ compared to the control group (Figure 1B).

Determination of the protective capacity of TSPO ligands against CS-induced cell death. The protective potential of the ligands in pretreatment application $24 \mathrm{~h}$ prior to $30-\mathrm{min}$ exposure of $\mathrm{H} 9 \mathrm{C} 2$ cells to $\mathrm{CS}$ was tested by evaluating the level of cell death. Death in cells exposed to CS for $30 \mathrm{~min}$ without ligand pretreatment was increased by $26 \%(p<0.001)$ as compared to the control group (Figure 2). The application of the ligand 2-Cl-MGV-1 at $25 \mu \mathrm{M}$ led to a significant decrease $(p<0.001)$ in cell death, reducing it to level comparable with that of the control group, while at $1 \mu \mathrm{M}$ it
A

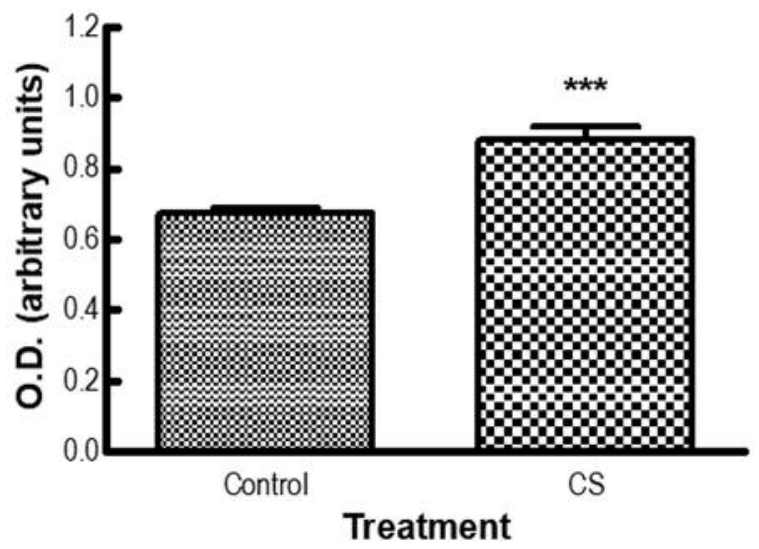

B

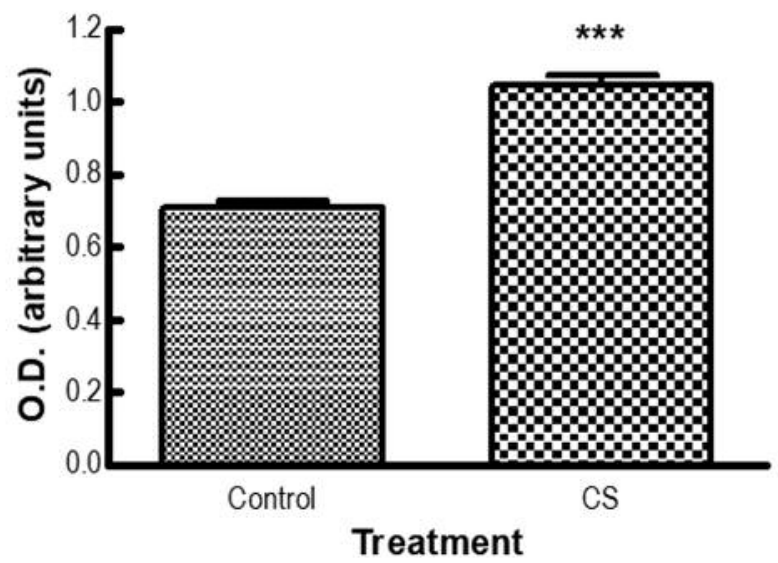

Figure 1. The effect of exposure to cigarette smoke (CS) on death of $H 9 C$ cardiomyocytes as measured by elevation in lactate dehydrogenase $(\mathrm{LDH})$ level in the medium. A: Cell death level following $30 \mathrm{~min}$ of CS exposure. B: Cell death level following $60 \mathrm{~min}$ of CS exposure. The results are presented as mean O.D. values (arbitrary units) \pm S.E.M $(n=12$ in each group). $* * *$ Statistically significant differences at $p<0.001$ as compared to the control group.

reduced cell death by $61 \%(p<0.01)$ as compared to the CS group (Figure 2A). In the case of MGV-1, application at 1 and $25 \mu \mathrm{M}$ as a pre-treatment reduced cell death by $50 \%$ $(p<0.05)$ and $62 \%(p<0.01)$, respectively, as compared to the CS group (Figure 2B).

Analysis of TSPO binding assay. The effect of CS on TSPO binding in our cellular model was performed. The mean results of four experiments are presented, showing a significant decrease in the binding level after $30 \mathrm{~min}$ of 

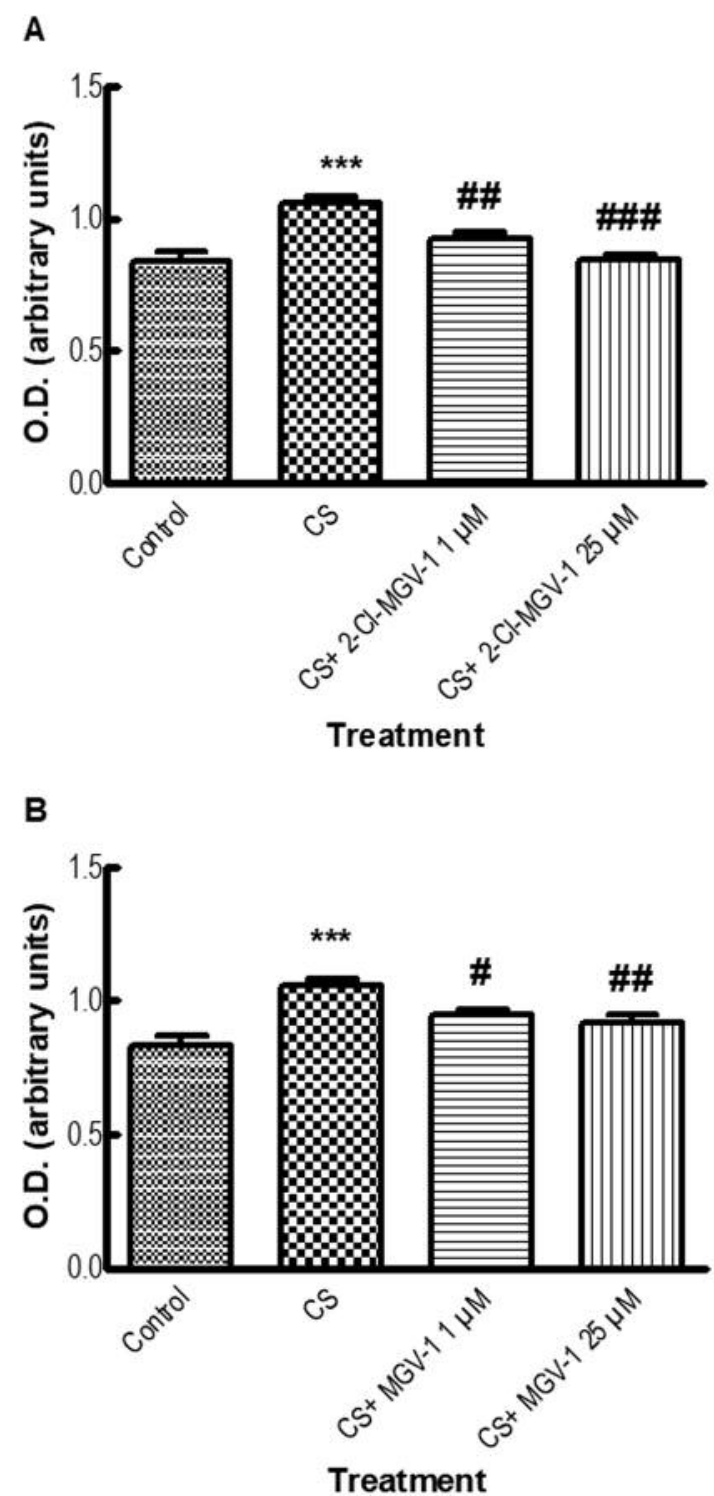

Figure 2. The effect of pre-treatment with translocator protein (TSPO) ligand on death in $\mathrm{H} 9 \mathrm{C} 2$ cardiomyocytes after exposure to cigarette smoke (CS) for $30 \mathrm{~min}$. A: Comparison of $\mathrm{H} 9 \mathrm{C} 2$ cell death in the CS group compared to the control group. The application of the TSPO ligand 2-Cl-MGV-1 at two different concentrations had a protective effect against CS-induced cell death. B: The protective effect of TSPO ligand MGV-1 against CS-induced death of $\mathrm{H} 9 \mathrm{C} 2$ cells. The results are expressed as the mean O.D. (arbitrary units) \pm S.E.M ( $n=4$ in each group). Significantly different at $* * * p<0.001$ compared to the control group; ${ }^{\#} p<0.05,{ }^{\# \#} p<0.01$, and ${ }^{\# \# \#} p<0.001$ compared to the CS group.

exposure to CS. In the control group, the mean binding level was $2531 \pm 536 \mathrm{fmol} / \mathrm{mg}$ protein (referred to as $100 \%$ ). Following CS exposure, the binding level significantly decreased to $616 \pm 277 \mathrm{fmol} / \mathrm{mg}$ protein ( $25 \%$ as compared to control). Since the inhibitory effects of the ligands on CS-

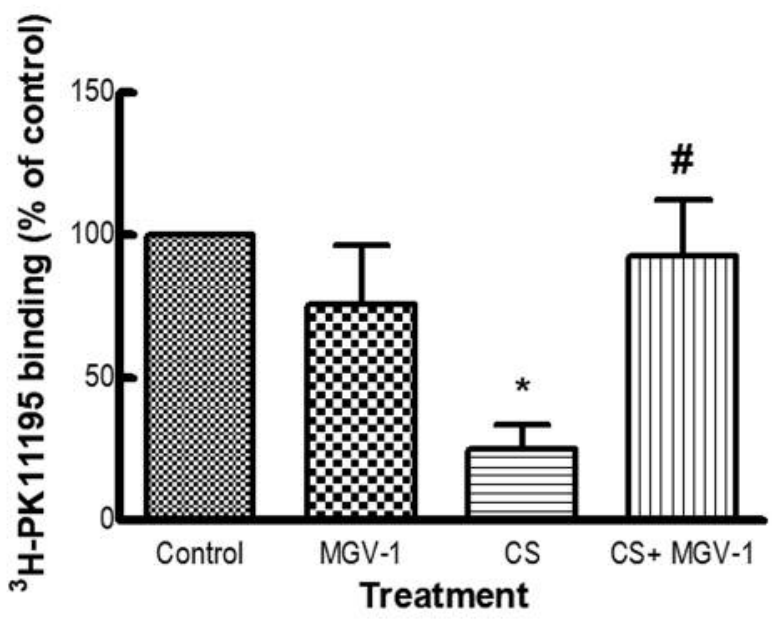

Figure 3. Protection by ligand MGV-1 (25 $\mu M)$ against cigarette smoke (CS)-induced reduction in translocator protein (TSPO) binding of ${ }^{3} \mathrm{H}$ labeled PK 11195 (6 nM) by H9C2 cardiomyocytes. The figure represents the mean percentage \pm S.E.M of the binding results of four experiments. Control: Cells not exposed to CS or ligand. Significantly different at $p<0.05$ compared to the *control group and ${ }^{\#} C S$ group.

induced $\mathrm{H} 9 \mathrm{C} 2$ cell death were similar, we only included the impact of MGV-1 as a representative ligand in the experiment on TSPO binding. Furthermore, MGV-1 is the scaffold of the other ligand. Pre-treatment with MGV-1 at a concentration of $25 \mu \mathrm{M}$ prevented the CS-induced loss of TSPO binding (83\% as compared to the control) $(p<0.05)$ (Figure 3$)$.

Western blot analysis. Western blot analysis was performed in order to measure the level of TSPO protein following 30 min of CS exposure. Five experiments were performed to measure the level of TSPO in the control and CS groups. CS exposure for $30 \mathrm{~min}$ did not result in a significant change in the expression of TSPO as compared to the control group (Figure 4).

TSPO levels on $\mathrm{H} 9 \mathrm{C} 2$ cells following $30 \mathrm{~min}$ of CS exposure were measured using FACS. TSPO expression was not altered significantly following CS exposure nor by the application of either TSPO ligands (Figure 5).

\section{Discussion}

The most important finding of the current study was the ability of the TSPO ligands MGV-1 and 2-Cl-MGV-1 to prevent in vitro CS-induced death of cardiomyocytes. It is likely that CS-induced cell death through TSPO occurs mainly via apoptotic cell death, as previously described for H1299 lung cancer cells (30). 2-Cl-MGV-1 at a concentration of $25 \mu \mathrm{M}$ was more protective than MGV-1, and practically completely prevented cell death, while MGV1 exhibited only a partially protective effect (62\%) Figure 
A

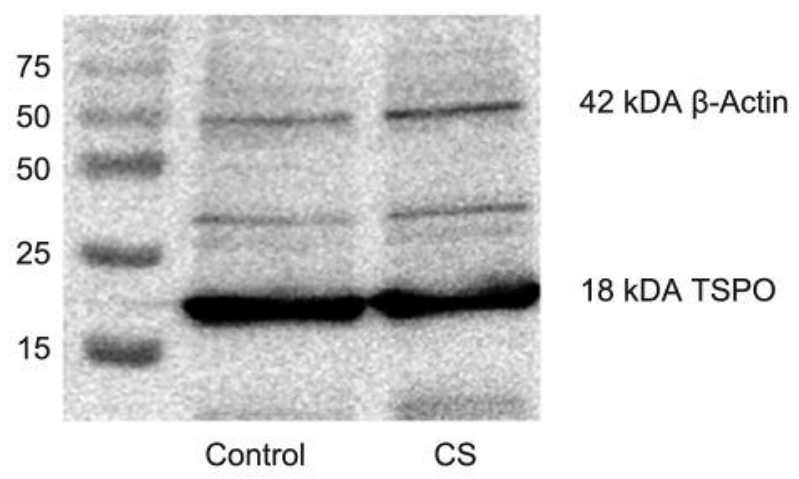

B

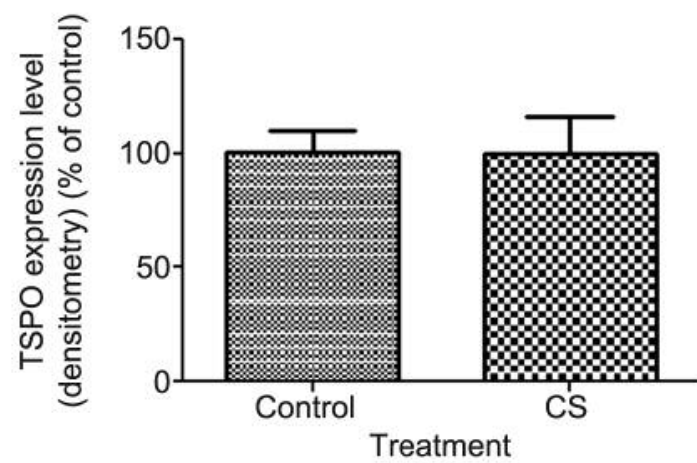

Figure 4. Translocator protein (TSPO) expression in control and cigarette smoke (CS)-exposed cells. A: A representative western blot analysis of TSPO expression in the control group and $\mathrm{H} 9 \mathrm{C} 2$ cardiomyocytes exposed for $30 \mathrm{~min}$ to CS. B: TSPO expression in the control group exposed to ambient air and $\mathrm{H} 9 \mathrm{C} 2$ cells exposed to CS. Results are expressed in relative O.D. (arbitrary units) of TSPO expression normalized to that of $\beta$-actin \pm S.E.M.

$2)$. It is of note that longer exposure to CS was more cytotoxic than short exposure to CS (60 versus 30 min: cell death rate $48 \%$ versus $30 \%$, Figure 1). Thus, in the present study we focused on the 30-min duration of CS exposure in an attempt to be able to demonstrate the protective effect of the ligands. In future studies, more time points and dose dependency experiments should be performed.

The present observation is consistent with previous studies demonstrating that exposure of lymphocytes or SCC-25 oral cancer cells to CS resulted in time-dependent cell death with survival rates of $56 \%$ and $61.6 \%$, respectively $(31,32)$. It is likely that the protective effect of the ligands, at least partially, is mediated by their interaction with TSPO, since the prevention of CS-induced cell death was associated with a parallel prevention of a decrease in TSPO binding.
The observed reduction in TSPO binding following CS exposure was reported in different cellular models (10, 3335). Interestingly, the CS-induced suppression of TSPO binding was not reflected in the western blot and FACS analysis of TSPO protein expression. This discrepancy may be related to the fact that the binding assay measures the protein content only in viable cells, while the protein analysis by western blot or FACS reflects the total protein content, irrespective of the viability of the cells. As for the mechanism by which CS affects cells, we suggest that among others, free radicals, transitional metal ions and aldehydes might cause severe cellular damage resulting in DNA aberrations that lead to cancer and other conditions, eventually resulting in cellular death $(31,32)$. Furthermore, the underlying mechanism by which CS reduces TSPO binding is unknown and may be the result of various CS-borne components such as complex metals or free radicals such as reactive oxygen species and volatile aldehydes (36). With regard to free radicals, in our laboratory we found that in a model in which oxidative stress was induced by dimethylbenz(alpha)anthracene, the binding capacity of the TSPO in rat aorta was reduced (37). However, recently we reported in another study, conducted in a totally different model, that CS-induced reduction in salivary TSPO binding was not mediated by an increase of free radicals (35). Regardless the exact mechanism and the specific CS components responsible for this phenomenon, it is clear that TSPO ligands can prevent a decrease in TSPO binding in cardiomyocytes exposed to CS.

The cellular pathways involved in the protective effect of the TSPO ligands against cellular death induced by CS are still unclear. In another relevant study, it was shown that TSPO ligands can also prevent initiation of cellular events (collapse of the mitochondrial membrane potential and generation of reactive oxygen species) leading to mitochondrial apoptosis cascade. Moreover, it was demonstrated that TSPO ligands, including the compounds examined here, can regulate cell death processes (21).

Limitations. The major limitation of the study is the CS model. The study was conducted by exposing rat-derived cardiomyocytes to smoke. In the human paradigm, this does not occur. Heart cells are exposed to certain constituents of CS and their metabolites via the circulation. Future study should include an alternative model using exposure of cardiomyocyte cells in culture directly with CS extract instead of exposure to all CS condensate. An alternative in vitro approach would be to generate extract of CS and supplement the growth medium with it at appropriate concentrations. The model most relevant to the clinical scenario would be to expose animals to cigarette smoke for a period of time and then conduct the study on primary cells derived from organs of interest from animals exposed to CS and those exposed to ambient air. In addition, it would also 
A

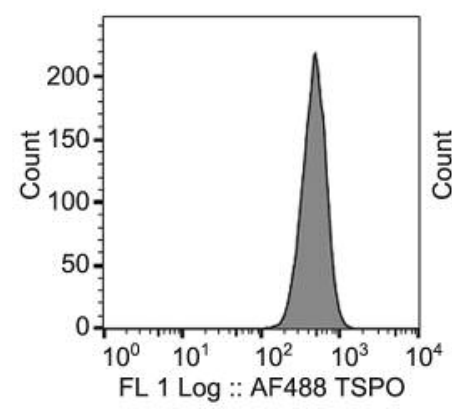

D

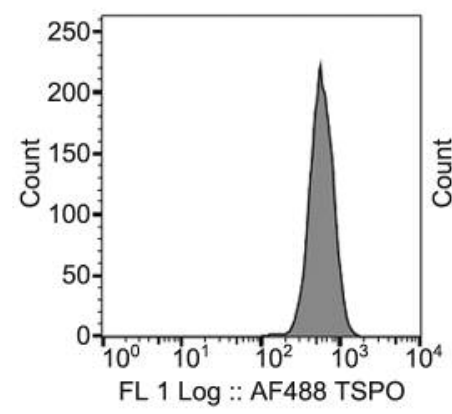

B

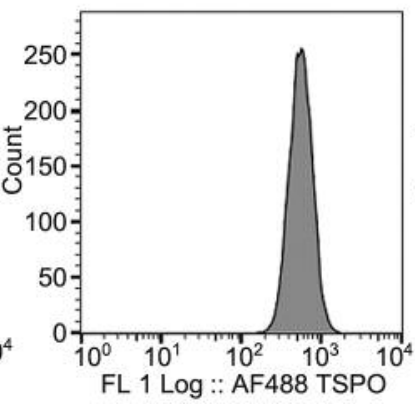

E

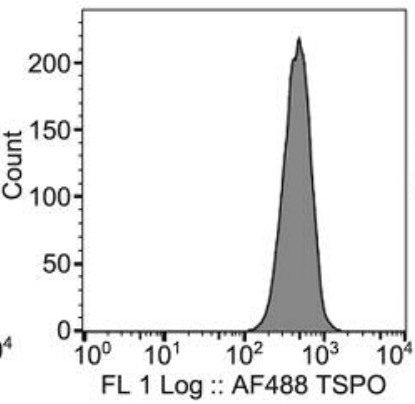

C

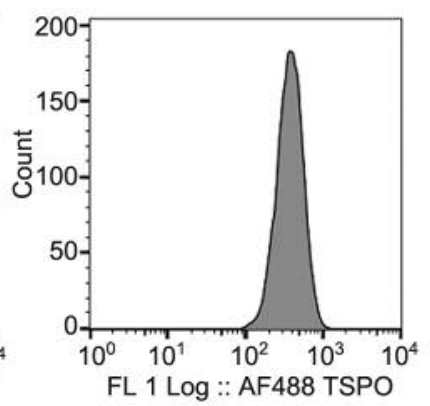

F

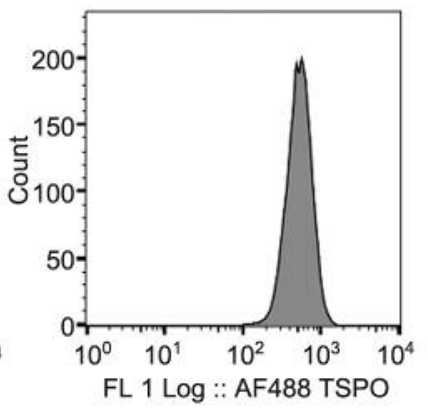

G

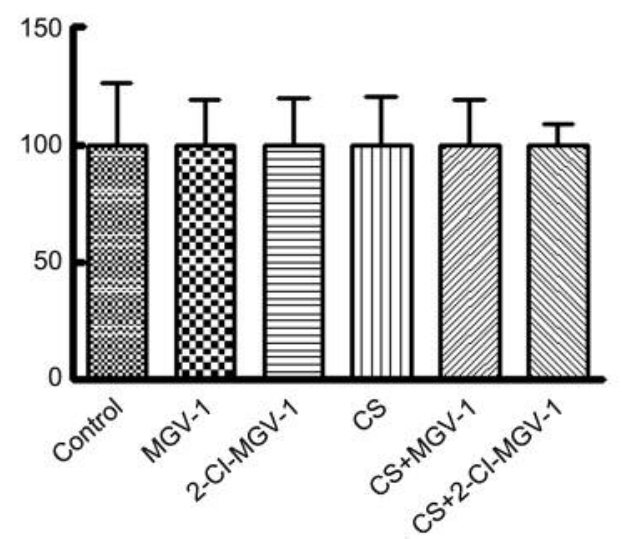

Treatment

Figure 5. Translocator protein (TSPO) expression in H9C2 cardiomyocytes represented by mean fluorescence intensity (MFI). A: Control group. B: Group treated with CS for $30 \mathrm{~min}$. C: Cells pretreated for $24 \mathrm{~h}$ with TSPO ligand MGV-1 without exposure to CS. D: Cells pretreated for $24 \mathrm{~h}$ with $25 \mu M$ TSPO ligand 2-Cl-MGV-1 without exposure to CS. E: Cells pretreated for $24 \mathrm{~h}$ with $25 \mu \mathrm{M}$ TSPO ligand MGV-1 prior to CS exposure. F: Cells pretreated for $24 \mathrm{~h}$ with $25 \mu \mathrm{M}$ TSPO ligand 2-Cl-MGV-1. G: Quantitative data for TSPO level in the different experimental groups. Results are represented are the mean MFI \pm S.E.M ( $n=4$ in each group).

be informative to examine in future studies whether administration of the ligands during CS exposure has a similar effect or reduces the extent of cellular damage. The second limitation of the study is the fact that the effects of the ligands in restoring downstream signaling, namely the pathways by which the restoration of TSPO signaling prevents CS-induced cell death, were not investigated. Furthermore, no studies were conducted to look at the classic markers of cell proliferation or apoptosis, therefore, it was not possible to determine whether cell death was due to necrosis, apoptosis, or autophagy. Future studies will be focused on the cellular processes involved in the protective 
effects of the ligands. Transcriptomic assessment of the cardiac cells exposed to CS compared with those in ambient air and receiving vehicle or treatment can help to uncover the potential mechanisms involved in this process.

\section{Conclusion}

The data presented here show that these TSPO ligands protect cells against CS-induced cellular death concomitantly with prevention of the CS-induced reduction in TSPO binding. One cannot overemphasize the potential importance of this finding, as tobacco in general, and CS in particular, are responsible for a huge amount of morbidity and mortality worldwide. Furthermore, the mechanistic significance of these findings indicates the pivotal role of TSPO in the cellular cascade of events, which begins with exposure to CS and ends with devastating diseases such as lung cancer, chronic obstructive pulmonary disease and cardiovascular diseases. The next phase should be complementary in vivo experiments where animals are exposed to CS following pharmacological or genetic manipulation of TSPO, as well as administration of TSPO ligands prior to CS exposure. Nevertheless, these results may be relevant to the prevention or treatment of cardiovascular diseases associated with CS.

\section{Conflicts of Interest}

None declared.

\section{Authors' Contributions}

RN co-designed the study and wrote the manuscript; NZ performed the experiments, analyzed data and co-wrote the Methods and Results sections; MA assisted in experimentation and data analysis; $\mathrm{NY}$ assisted in experimentation and data analysis; AW performed critical reading and editing of the manuscript; MG co-designed the study and edited the manuscript.

\section{References}

1 Veenman L and Gavish M: The peripheral-type benzodiazepine receptor and the cardiovascular system. Implications for drug development. Pharmacol Ther 110: 503-524, 2006. PMID: 16337685. DOI: $10.1016 /$ j.pharmthera 2005.09 .007

2 Veenman L and Gavish M: The role of $18 \mathrm{kDa}$ mitochondrial translocator protein (TSPO) in programmed cell death, and effects of steroids on TSPO expression. Curr Mol Med 12: 398-412, 2012. PMID: 22348610. DOI: $10.2174 / 15665240$ 11207040398

3 Caballero A, Torres-Duque CA, Jaramillo C, Bolivar F, Sanabria F, Osorio P, Orduz C, Guevara DP and Maldonado D: Prevalence of COPD in five Colombian cities situated at low, medium, and high altitude (Prepocol study). Chest 133: 343-349, 2008. PMID: 17951621. DOI: 10.1378/chest.07-1361
4 Veenman L, Bode J, Gaitner M, Caballero S, Pe'er Y, Zeno S, Kietz S, Kugler W, Lakomek M and Gavish M: Effects of 18-kDa translocator protein knockdown on gene expression of glutamate receptors, transporters, and metabolism, and on cell viability affected by glutamate. Pharmacogenet Genomics 22: 606-619, 2012. PMID: 22732722. DOI: 10.1097/FPC.0b013e3283544531

5 Veenman L, Gavish M and Kugler W: Apoptosis induction by erucylphosphohomocholine via the $18 \mathrm{kDa}$ mitochondrial translocator protein: implications for cancer treatment. Anticancer Agents Med Chem 24: 559-577, 2014. PMID: 24628235. DOI: $10.2174 / 1871520614666140309230338$

6 Bode J, Veenman L, Caballero B, Lakomek M, Kugler W and Gavish M: The 18-kDa translocator protein influences angiogenesis, as well as aggressiveness, adhesion, migration, and proliferation of glioblastoma cells. Pharmacogenet Genomics 22: 538-550, 2012. PMID: 22547081. DOI: 10.1097/FPC.0b013e3283539cdc

7 Papadopoulos V, Baraldi M, Guilarte TR, Knudsen TB, Lacapère JJ, Lindemann P, Norenberg MD, Nutt D, Weizman A, Zhang MR and Gavish M: Translocator protein (18kDa): new nomenclature for the peripheral-type benzodiazepine receptor based on its structure and molecular function. Trends Pharmacol Sci 27: 402-409, 2006. PMID: 16822554. DOI: 10.1016/ j.tips.2006.06.005

8 Ruksha $\mathrm{T}$, Aksenenko $\mathrm{M}$ and Papadopoulos V: Role of translocator protein in melanoma growth and progression. Arch Dermatol Res 304: 839-845, 2012. PMID: 23080515. DOI: 10.1007/s00403-012-1294-5

9 Gavish M, Bachman I, Shoukrun R, Katz Y, Veenman L, Weisinger $\mathrm{G}$ and Weizman A: Enigma of the peripheral benzodiazepine receptor. Pharmacol Rev 51: 629-650, 1999. PMID: 10581326.

10 Nagler R, Savulescu D, Krayzler E, Leschiner S, Veenman L and Gavish M: Cigarette smoke decreases salivary 18-kDa translocator protein binding affinity-in association with oxidative stress. Curr Med Chem 17: 2539-2546, 2010. PMID: 20491643. DOI: $10.2174 / 092986710791556050$

11 World Health Organization: WHO Report on the Global Tobacco Epidemic, 2011. Geneva: World Health Organization, 2011 (accessed 2015 Apr 7).

12 Jha P, Ramasundarahettige C, Landsman V, Rostron B, Thun M, Anderson RN, McAfee T and Peto R: 21st century hazards of smoking and benefits of cessation in the United States. New Engl J Med 368: 341-350, 2013. PMID: 23343063. DOI: 10.1056/NEJMsa1211128

13 U.S. Department of Health and Human Services: The Health Consequences of Smoking-50 Years of Progress: A Report of the Surgeon General. (http://www.cdc.gov/tobacco/data_statistics/ $\mathrm{sgr} / 50^{\text {th }}$-anniversary/index.htm) Atlanta: U.S. Department of Health and Human Services, Centers for Disease Control and Prevention, National Center for Chronic Disease Prevention and Health Promotion, Office on Smoking and Health, 2014 (accessed 2015 Apr 7).

14 Bhalla DK, Hirata F, Rishi AK and Gairola CG: Cigarette smoke, inflammation, and lung injury: A mechanistic perspective. J Toxicol Environ Health B Crit Rev 12: 45-64, 2009. PMID: 19117209 . DOI: $10.1080 / 10937400802545094$

15 Alberg AJ and Samet JM: Epidemiology of lung cancer. Chest 123: 21S-49S, 2003. PMID: 12527563. DOI: 10.1378/chest. 123.1_suppl.21s

16 Kung HC, Hoyert DL, Xu J and Murphy SL: Deaths: Final data for 2005. Natl Vital Stat Rep 56: 1-120, 2008. PMID: 18512336. 
17 Skillrud DM, Offord KP and Miller RD: Higher risk of lung cancer in chronic obstructive pulmonary disease: a prospective, matched, controlled study. Ann Intern Med 105: 503-507, 1986. PMID: 3752756. DOI: 10.7326/0003-4819-105-4-503

18 Caballero B, Veenman L and Gavish M: Role of mitochondrial translocator protein $(18 \mathrm{kDa})$ on mitochondrial related cell death processes. Recent Pat Endocr Metab Immune Drug Discov 7: 86-101, 2013. PMID: 23368281. DOI: 10.2174/1872214811 307020002

19 Halliwell B and Gutteridge JM: Role of free radicals and catalytic metal ions in human disease: An overview. Methods Enzymol 186: 1-85, 1990. PMID: 2172697. DOI: 10.1016/00766879(90)86093-b

20 Domagala-Kulawik J: Effects of cigarette smoke on the lung and systemic immunity. J Physiol Pharmacol 59 Suppl 6: 19-34, 2008. PMID: 19218630.

21 Vainshtein A, Veenman L, Shterenberg A, Singh S, Masarwa A, Dutta B, Island B, Tsoglin E, Levin E, Leschiner S, Maniv I, Pe'er L, Otradnov I, Zubedat S, Mizrachi S, Weizman A, Avital A, Marek I and Gavish M: Quinazoline-based tricyclic compounds that regulate programmed cell death, induce neuronal differentiation, and are curative in animal models for excitotoxicity and hereditary brain disease. Cell Death Disc 1: 15027, 2015. PMID: 27551459. DOI: 10.1038/cddiscovery. 2015.27

22 Monga S, Nagler R, Amara R, Weizman A and Gavish M: Inhibitory effects of the two novel TSPO ligands 2-Cl-MGV-1 and MGV-1 on LPS-induced microglial activation. Cells 8: pii: E486, 2019. PMID: 31121852. DOI: 10.3390/cells8050486

23 Azrad M, Zeineh N, Weizman A, Veenman L and Gavish M: The TSPO ligands 2-Cl-MGV-1, MGV-1, and PK11195 differentially suppress the inflammatory response of BV-2 microglial cell to LPS. Int J Mol Sci 20: pii: E594, 2019. PMID: 30704062. DOI: 10.3390/ijms20030594

24 Rom O, Kaisari S, Aizenbud D and Reznick AZ: Cigarette smoke and muscle catabolism in C2 myotubes. Mech Age Dev 134: 24-34, 2013. PMID: 23262287. DOI: 10.1016/j.mad. 2012.11.004

25 Weiner D, Levy Y, Khankin EV and Reznick AZ: Inhibition of salivary amylase activity by cigarette smoke aldehydes. J Physiol Pharmacol 59 (Suppl 6): 727-737, 2008. PMID: 19218700

26 Avezov K, Reznick AZ and Aizenbud D: Oxidative damage in keratinocytes exposed to cigarette smoke and aldehydes. Toxicol in Vitro 28: 485-491, 2014. PMID: 24444448. DOI: 10.1016/ j.tiv.2014.01.004

27 Legrand C, Bour JM, Jacob C, Capiaumont D, Martial A, Marc A, Wudtke M, Kretzmer G, Demangel C, Duval D and Hache J: Lactate dehydrogenase (LDH) activity of the cultured eukaryotic cells as marker of the number of dead cells in the medium (corrected). J Biotechnol 25: 231-43, 1992. PMID: 1368802. DOI: $10.1016 / 0168-1656(92) 90158-6$
28 Bradford MM: A rapid and sensitive method for the quantitation of microgram quantities of protein utilizing the principle of protein-dye binding. Anal Biochem 72: 248-254, 1976. PMID: 942051. DOI: 10.1006/abio.1976.9999

29 Zeno S, Zaaroor M, Leschiner S, Veenman L and Gavish M: $\mathrm{CoCl}(2)$ induces apoptosis via the $18 \mathrm{kDa}$ translocator protein in U118MG human glioblastoma cells. Biochemistry 48: 46524661, 2009. PMID: 19358520. DOI: 10.1021/bi900064t

30 Zeineh N, Nagler R, Gabay M, Weizman A and Gavish M: Effects of cigarette smoke on TSPO-related mitochondrial processes. Cells 8: pii: E694, 2019. PMID: 31295884. DOI: 10.3390/cells8070694

31 Reznick AZ, Hershkovich O and Nagler RM: Saliva--a pivotal player in the pathogenesis of oropharyngeal cancer. Br J Cancer 91: 111-118, 2004. PMID: 15162153. DOI: 10.1038/sj.bjc. 6601869

32 Hasnis E, Reznick AZ, Pollack S, Klein Y and Nagler RM: Synergistic effect of cigarette smoke and saliva on lymphocytes-the mediatory role of volatile aldehydes and redox active iron and the possible implications for oral cancer. Int J Biochem Cell Biol 36: 826-839, 2004. PMID: 15006635. DOI: 10.1016/ j.biocel.2003.09.003

33 Nagler R, Ben-Izhak O, Savulescu D, Krayzler E, Akrish L, Leschiner L, Otradnov O, Zeno S, Veenman L and Gavish M: Oral cancer, cigarette smoke and mitochondrial $18 \mathrm{kDa}$ translocator protein (TSPO) - In vitro, in vivo, salivary analysis. Biochim Biophys Acta 1802: 454-461, 2010. PMID: 20085808. DOI: $10.1016 /$ j.bbadis .2010 .01 .008

34 Nagler R, Cohen S and Gavish M: The effect of cigarette smoke on the translocator protein (TSPO) in cultured lung cancer cells. J Cell Biochem 116: 2786-2792, 2015. PMID: 25968977. DOI: $10.1002 /$ jcb. 25221

35 Nagler R, Savulescu D and Gavish M: Cigarette smoke-induced reduction in binding of the salivary translocator protein is not mediated by free radicals. Biochimie 121: 1-4, 2016. PMID: 26582415. DOI: 10.1016/j.biochi.2015.11.011

36 Pryor WA: Cigarette smoke and the involvement of free radical reactions in chemical carcinogenesis. Br J Cancer 55: 19-23, 1987. PMID: 3307870.

37 Dimitrova-Shumkovska J, Veenman L, Ristoski T, Leschiner S and Gavish M: Dimethylbenz(alpha)anthracene induces oxidative stress and reduces the binding capacity of the mitochondrial $18-\mathrm{kDa}$ translocator protein in rat aorta. Drug Chem Toxicol 33: 337-347, 2010. PMID: 20550435. DOI: $10.3109 / 01480540903483441$ 